\title{
In situ X-Ray Powder Diffraction Studies of Hydrogen Storage and Release in the Li-N-H System
}

\author{
Joshua W. Makepeace, ${ }^{a}$ Martin O. Jones, ${ }^{b}$ Samantha K. Callear, ${ }^{b}$ Peter P. Edwards ${ }^{a}$ and William I.F. \\ David $^{a, b *}$
}

\author{
Received (in $X X X, X X X)$ Xth $X X X X X X X X X 20 X X$, Accepted Xth $X X X X X X X X X 20 X X$ \\ DOI: $10.1039 / b 000000 x$
}

\begin{abstract}
We report the experimental investigation of hydrogen storage and release in the lithium amide - lithium hydride composite $(\mathrm{Li}-\mathrm{N}-\mathrm{H})$ system. Investigation of hydrogenation and dehydrogenation reactions of the 10 system through in situ synchrotron X-ray powder diffraction experiments allowed for the observation of the formation and evolution of non-stoichiometric intermediate species of the form $\mathrm{Li}_{1+\mathrm{x}} \mathrm{NH}_{2-\mathrm{x}}$. This result is consistent with the proposed Frenkel-defect mechanism for these reactions. We observed capacity loss with decreasing temperature through decreased levels of lithium-rich $(0.7<\mathrm{x}<1.0)$ non-stoichiometric phases in the dehydrogenated material, but only minor changes due to multiple cycles at the same

15 temperature. Annealing of dehydrogenated samples reveals the reduced stability of intermediate stoichiometry values $(0.7<\mathrm{x}<1.0)$ compared with the end member species: lithium amide $\left(\mathrm{LiNH}_{2}\right)$ and lithium imide $\left(\mathrm{Li}_{2} \mathrm{NH}\right)$. Our results highlight the central role of ionic mobility in understanding temperature limitations, capacity loss and facile reversibility of the Li-N-H system.
\end{abstract}

\section{Introduction}

20 The twin drivers of energy security and environmental concern have led to the pursuit of alternative methods of fuelling transportation. Hydrogen is seen as an attractive fuel due to its high gravimetric energy density and clean emissions profile at the point of use. ${ }^{1,2}$ Much research effort has therefore been expended 25 in order to find a materials-based method of storing hydrogen, with the aim of improving volumetric energy density relative to gaseous hydrogen.

Despite these efforts, effective solid state hydrogen storage remains an elusive goal in the transition towards sustainable, 30 hydrogen-based transportation. Although many systems have been investigated, there have been few significant advances towards a truly practical system since work by Schwickardi and Bogdanovic in 1997. ${ }^{3}$ Most complex metal hydrides with sufficient volumetric and gravimetric hydrogen density lack an 35 acceptably low hydrogen release temperature and are poorly reversible. ${ }^{4}$ Given the lack of success in the development of commercially viable solid state hydrogen storage materials, we believe a realigned focus on the mechanisms of hydrogen storage and release in complex hydride materials is essential, particularly

40 amongst canonical systems that already display desirable characteristics.

One such system, the lithium amide-lithium hydride composite ( $\mathrm{Li}-\mathrm{N}-\mathrm{H})$ was first highlighted as a potential hydrogen store over a decade ago, ${ }^{5,6}$ and remains a subject of interest ${ }_{45}$ because of its facile reversibility. ${ }^{7,8}$ In this system, the storage of hydrogen by lithium nitride $\left(\mathrm{Li}_{3} \mathrm{~N}\right)$ occurs in two stages (Equations 1-2).

$$
{ }_{50} \mathrm{Li}_{2} \mathrm{NH}+\mathrm{H}_{2} \leftrightarrow \mathrm{LiNH}_{2}+\mathrm{LiH}(2)
$$

Combined, the overall reaction results in a hydrogen storage capacity of $10.4 \mathrm{wt} \%$, with a corresponding volumetric hydrogen density of $100.3 \mathrm{kgH}_{2} \mathrm{~m}^{-3}$ (for comparison, the volumetric 55 hydrogen density of liquid hydrogen at $20 \mathrm{~K}$ is $70 \mathrm{kgH}_{2} \mathrm{~m}^{-3}$ ). However, the first stage of hydrogenation of lithium nitride is highly exothermic and thus the dehydrogenation (reverse reaction of Equation 1) will only occur above $700 \mathrm{~K} .^{5}$ The conversion of lithium imide $\left(\mathrm{Li}_{2} \mathrm{NH}\right)$ to lithium amide $\left(\mathrm{LiNH}_{2}\right)$ and lithium ${ }_{60}$ hydride $(\mathrm{LiH})$ (Equation 2), stores $6.5 \mathrm{wt} \%$ hydrogen $(67.3$ $\left.\mathrm{kgH}_{2} \mathrm{~m}^{-3}\right)$, occurs at a much lower enthalpy $\left(-67 \mathrm{kJmol}^{-1}\right)^{9}$ and is accessible at lower temperatures $(500 \mathrm{~K})$ with modest hydrogen pressures (1-10 bar).

With the desire to approach commercial performance targets, ${ }^{10}$ a ${ }_{65}$ number of groups have attempted to elucidate the precise mechanism of hydrogen storage in the Li-N-H system, and thus identify the physical parameters that govern the conditions of these hydrogenation/dehydrogenation processes. Hydrogen release from $\mathrm{LiNH}_{2}$ and $\mathrm{LiH}$ is proposed to be an ammonia70 mediated process, ${ }^{11}$ wherein the ammonia released from the decomposition of $\mathrm{LiNH}_{2}$ (Equation 3) is captured by $\mathrm{LiH}$ (Equation 4), to form $\mathrm{Li}_{2} \mathrm{NH}$, with the concomitant release of 

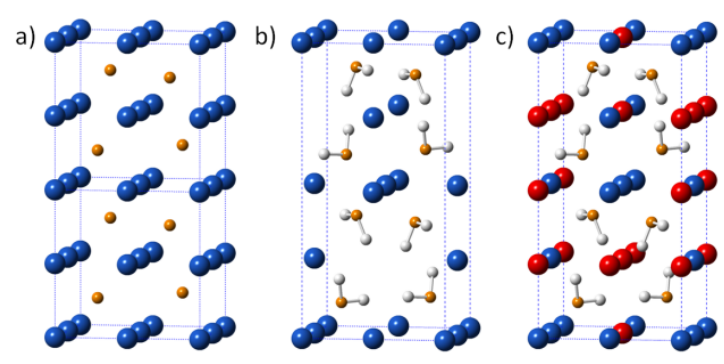

Fig. 1 Crystal structures in the Li-N-H system, with lithium ions shown in blue, nitrogen shown in orange, and hydrogen in white: a) the $\mathrm{a} \times \mathrm{a} \times 2 \mathrm{a}$ super cell of the high temperature phase of Li2NH, with the origin shifted by $(1 / 4,1 / 4,1 / 4)$ and hydrogen atoms omitted for clarity; b) the LiNH2 unit 5 cell; and c) LiNH2 with vacant lithium sites shown in red.

hydrogen:

$$
\begin{aligned}
& 2 \mathrm{LiNH}_{2} \leftrightarrow \mathrm{Li}_{2} \mathrm{NH}+\mathrm{NH}_{3} \\
& \mathrm{LiH}+\mathrm{NH}_{3} \leftrightarrow \mathrm{LiNH}_{2}+\mathrm{H}_{2}
\end{aligned}
$$

Following on from experiments which supported this 10 model $^{12,13}$, ex situ synchrotron X-ray powder diffraction studies on hydrogenated and dehydrogenated $\mathrm{Li}-\mathrm{N}-\mathrm{H}$ samples afforded the necessary resolution for a more comprehensive mechanism to be proposed ${ }^{14}$. Complex microstructure observed in the diffraction peaks of lithium amide and imide indicated significant 15 deviation in stoichiometry for samples supposedly at the end of their hydrogenation and dehydrogenation cycles, respectively. Rietveld analysis of these data modelled the peaks using a series of non-stoichiometric intermediates of the form $\mathrm{Li}_{1+x} \mathrm{NH}_{2-\mathrm{x}}$.

The crystal structure of $\mathrm{LiNH}_{2}$ is an $a \times a \times 2 a$ ordered supercell 20 of the anti-fluorite structure of $\mathrm{Li}_{2} \mathrm{NH}$ with half the lithium sites vacant (Figure 1). Noting this topological similarity, together with the evidence for lithium ion diffusion in another $\mathrm{Li}_{2} \mathrm{NH}$ analogue, lithium oxide $\left(\mathrm{Li}_{2} \mathrm{O}\right),{ }^{15,16}$ a Frenkel-pair based mechanism for the hydrogen desorption (Equations 5-8) and 25 absorption (Equations 9-11) in the Li-N-H system $^{14}$ was proposed, and has since been supported by first-principles calculations. ${ }^{17-19}$ The mechanism is shown in Equations 5-11, where a $\square$ symbol denotes a lithium ion vacancy, and depicted in Figure 2.

30

$$
\begin{aligned}
& \mathrm{LiNH}_{2}+\mathrm{LiNH}_{2} \leftrightarrow\left[\square \mathrm{NH}_{2}\right]^{-}+\left[\mathrm{LiLiNH}_{2}\right]^{+} \\
& {\left[\mathrm{LiLiNH}_{2}\right]^{+} \leftrightarrow \mathrm{Li}_{2} \mathrm{NH}+\mathrm{H}^{+}} \\
& {\left[\square \mathrm{NH}_{2}\right]^{-}+\mathrm{H}^{+} \leftrightarrow \mathrm{NH}_{3}} \\
& \mathrm{NH}_{3}+\mathrm{LiH} \leftrightarrow \mathrm{LiNH}_{2}+\mathrm{H}_{2}
\end{aligned}
$$

$$
\begin{aligned}
& \mathrm{Li}_{2} \mathrm{NH} \leftrightarrow \mathrm{Li}^{+}+[\square \mathrm{LiNH}]^{-} \\
& \mathrm{Li}^{+}+\mathrm{H}_{2} \leftrightarrow \mathrm{LiH}+\mathrm{H}^{+} \\
& {[\square \mathrm{LiNH}]^{-}+\mathrm{H}^{+} \leftrightarrow \mathrm{LiNH}_{2}}
\end{aligned}
$$

40 The structural similarity of $\mathrm{LiNH}_{2}$ and $\mathrm{Li}_{2} \mathrm{NH}$ facilitates the migration of both $\mathrm{Li}^{+}$and $\mathrm{H}^{+}$, and thus underpins the relatively facile solid state reversibility seen in the Li-N-H system. ${ }^{8}$ The ionic conductivity of $\mathrm{LiNH}_{2}$ at $520 \mathrm{~K}$ is $2.6 \times 10^{-5} \mathrm{Scm}^{-1}$, while $\mathrm{Li}_{2} \mathrm{NH}$ exhibits ionic conductivity of $5.3 \mathrm{Scm}^{-1}$ at $533 \mathrm{~K}^{20}$ Despite 45 the modest gravimetric hydrogen capacity of the Li-N-H system compared with light metal borohydrides and amidoboranes, the Li-N-H system remains a prototypic candidate for practical solid state hydrogen storage because of this superior reversibility.

Given the recent progress in the removal of trace levels of
50 ammonia through the use of transition metal halides supported on inert porous materials, ${ }^{21}$ the central barrier to utilization of Li-N$\mathrm{H}$ in PEM-based transportation is the high temperature of operation. While some reductions in operating temperature have been observed through the use of transition metal dopants, ${ }^{22-24}$ 55 significant development is needed in this area before commercial uptake is feasible. This requirement, together with recent results showing dramatically improved cycle lifetime and reversible hydrogen content with the addition of nitrogen gas in the hydrogenation gas stream, ${ }^{25}$ provides the impetus for obtaining a ${ }_{60}$ deeper insight into the reaction mechanism in the Li-N-H system. Here, we report the results of our in situ, high-resolution synchrotron X-ray diffraction investigation into the hydrogen storage and release mechanisms in the Li-N-H system. We observe the formation and dynamic behaviour of non65 stoichiometric intermediates as a function of time, temperature and hydrogenation pressure. We find that the properties of these intermediate phases are crucial in determining the extent of reaction and the cycle stability of the system.

\section{Experimental}

${ }_{70}$ Lithium nitride $\left(\mathrm{Li}_{3} \mathrm{~N}\right.$, Sigma Aldrich, $\left.>99.5 \%\right)$ was ground by hand for five minutes in an inert atmosphere glove box and then placed inside a single crystal sapphire capillary $(1 \mathrm{~mm})$, with quartz wool to plug the sample at each end of the capillary. The capillary was housed within a custom-built high pressure sample 75 environment, allowing gas pressures of up to 100 bar. $^{26}$ Synchrotron X-ray diffraction data were collected on the I1 1 high resolution powder diffraction beamline $(\lambda=0.8186107 \AA)$ at the Diamond Light Source. The lithium nitride sample was confirmed to contain only $\alpha$ - and $\beta$ - lithium nitride as crystalline 80 phases. The system was evacuated and leak tested with helium gas before the addition of hydrogen via a gas panel, with sample

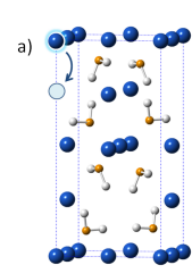

d)

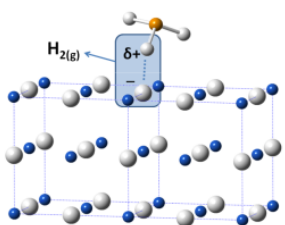

b)
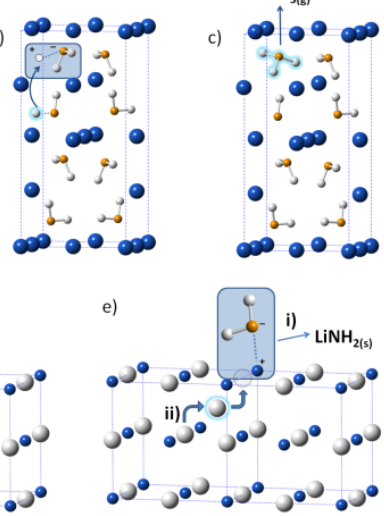

Fig. 2 The mechanism of hydrogen release in the Li-N-H system, with lithium ions shown in blue, nitrogen shown in orange, and hydrogen in white (a) A lithium ion forms a Frenkel defect pair by moving onto an 85 interstitial site in the $\mathrm{LiNH}_{2}$ structure. The local charge balance can be restored by the ejection of a proton from an $\mathrm{NH}_{2}^{-}$unit (b). This proton can then form an $\mathrm{NH}_{3}$ unit with the other half of the Frenkel defect (c). Once an $\mathrm{NH}_{3}$ unit reaches the surface, it is free to interact with lithium hydride (d), where the partially positively charged hydrogen on the $\mathrm{NH}_{3}$ molecule 90 will react with a hydride anion to form hydrogen gas. The remnant $\mathrm{NH}_{2}{ }^{-}$ unit can then react with a lithium ion to form lithium amide (e-i), and hydride anions can migrate to the surface (e-ii), leaving a Schottky defect. 


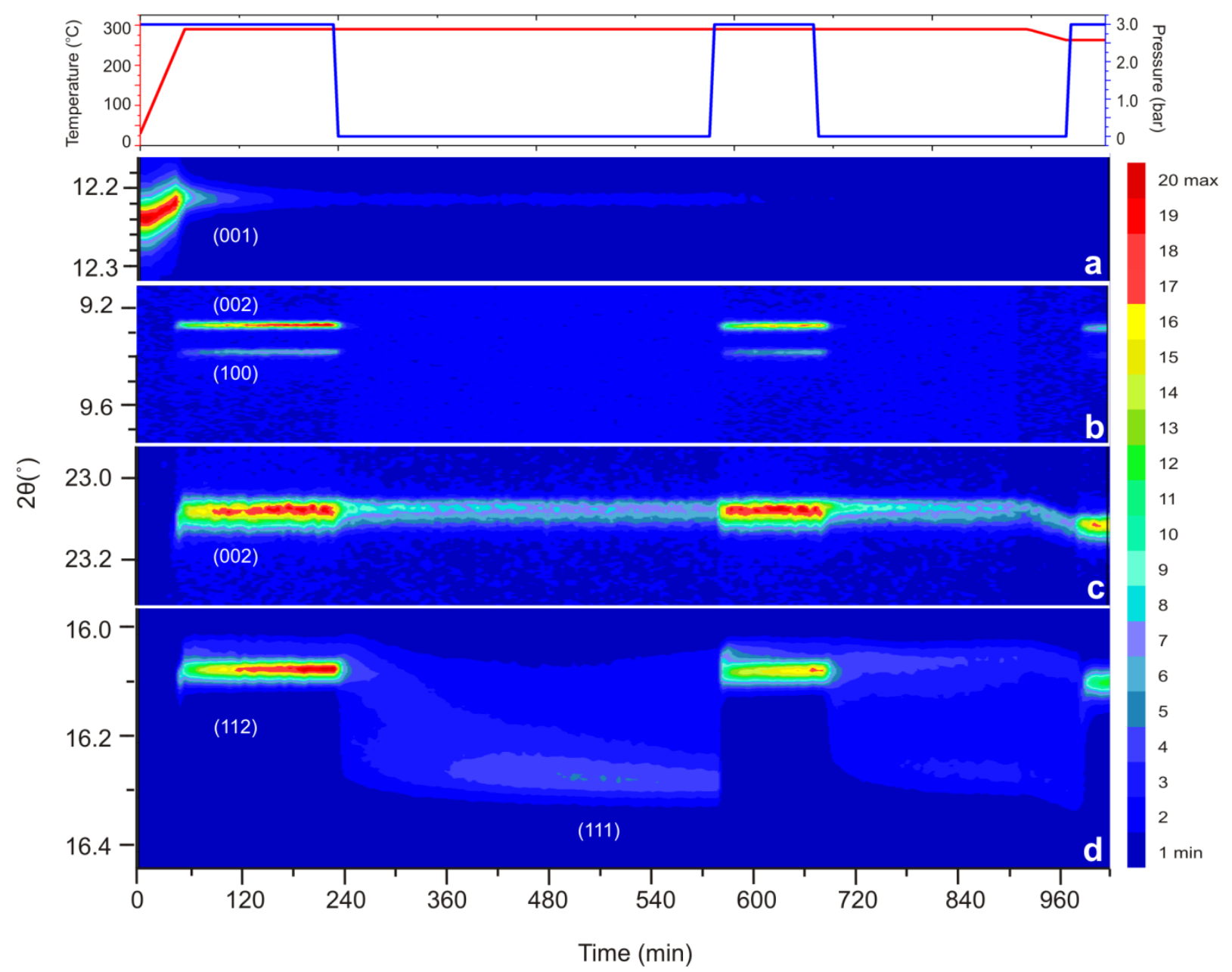

Fig. 3 Contour plot showing selected regions of the diffraction patterns obtained for the first two hydrogenation/dehydrogenation cycles (Processes A-E). The panels show a) the $\alpha-\mathrm{Li}_{3} \mathrm{~N}(001)$ reflection, b) the super-lattice region of $\mathrm{LiNH}_{2}$, the (002) and (100), c) the $\mathrm{LiH}(002)$ reflection and d) the "Li-N-H" region, bounded by the $\mathrm{LiNH}_{2}$ (112) reflection and the $\mathrm{Li}_{2} \mathrm{NH}$ (111) reflection. The top panel indicates the experimental conditions during the course of the experiment. The colour bar on the right hand side indicates the range of diffraction intensity within an individual panel. Individual reflections are indicated in white.

Table 1 Summary of pressure and temperature regimes for the in situ $\mathrm{X}$ ray diffraction measurements on the Li-N-H system. Letter designations given to the right of each set of reaction conditions indicate the sequence 10 in which each reaction was performed. All dehydrogenations were performed under dynamic vacuum.

\begin{tabular}{|c|c|c|}
\hline Process & Reaction conditions & Order \\
\hline $\mathrm{Li}_{3} \mathrm{~N}+2 \mathrm{H}_{2} \rightarrow \mathrm{LiNH}_{2}+2 \mathrm{LiH}$ & $290^{\circ} \mathrm{C}, 3$ bar H $\mathrm{H}_{2}$ & (A) \\
\hline $\mathrm{LiNH}_{2}+\mathrm{LiH} \rightarrow \mathrm{Li}_{2} \mathrm{NH}+\mathrm{H}_{2}$ & $290^{\circ} \mathrm{C}$ & (B) \\
& $290^{\circ} \mathrm{C}$ & (D) \\
& $263^{\circ} \mathrm{C}$ & (F) \\
& $235^{\circ} \mathrm{C}$ & (H) \\
& $235^{\circ} \mathrm{C}$ & (J) \\
& & \\
\hline $\mathrm{Li}_{2} \mathrm{NH}+\mathrm{H}_{2} \rightarrow \mathrm{LiNH}_{2}+\mathrm{LiH}$ & $290^{\circ} \mathrm{C}, 3$ bar H $\mathrm{H}_{2}$ & (C) \\
& $263^{\circ} \mathrm{C}, 3$ bar H $\mathrm{H}_{2}$ & (E) \\
& $235^{\circ} \mathrm{C}, 3$ bar H & (G) \\
& $235^{\circ} \mathrm{C}, 1$ bar H & (I) \\
& $235^{\circ} \mathrm{C}, 0.5$ bar H & (K) \\
& & \\
\hline
\end{tabular}

heating achieved using a hot-air blower. Due to the geometrical setup of the surrounding cell, and the high thermal conductivity of the sapphire capillary, it was necessary to conduct a 15 temperature calibration (details included in the Supplementary

\section{Information).}

After initial hydrogenation to form lithium amide and two equivalents of lithium hydride, the sample was cycled between the hydrogenated and dehydrogenated states under a number of 20 pressure and temperature regimes, as shown in Table 1.

Multi analyser crystal (MAC) Si (111) detectors were used to collect the high resolution X-ray diffraction data, collected in the $2 \theta$ range of $2-150^{\circ}$ with a step size of $0.001^{\circ}$. The data were rebinned into $0.005^{\circ}$ steps prior to analysis.

25 Rietveld refinement of the diffraction data was performed using the TOPAS Academic ${ }^{27}$ software package. Nonstoichiometric phases were modelled as a series of discrete phases, with a linear variation in stoichiometry between $\mathrm{LiNH}_{2}$ and $\mathrm{Li}_{2} \mathrm{NH}$ (i.e. $\mathrm{Li}_{1+x} \mathrm{NH}_{2-x}, 0 \leq \mathrm{x} \leq 1$, with increments of 0.1 ), 30 with the assumption that the $a$ lattice parameter of the cubic antifluorite lattice of these species varies linearly with stoichiometry, such that $a_{\mathrm{x}}=a_{\mathrm{low}}+0.1 \mathrm{x}\left(a_{\text {high }}-a_{\mathrm{low}}\right) .{ }^{14}$ Further details of the refinements may be found in the Supplementary Information.

\section{Results and Discussion}

35 A broad view of the reaction progression is detailed in Figure 3, 
Fig. 4 Contour plot of three sections of synchrotron X-ray diffraction data for the dehydrogenation of $\mathrm{LiNH}_{2}$ under vacuum at $290^{\circ} \mathrm{C}$, showing the

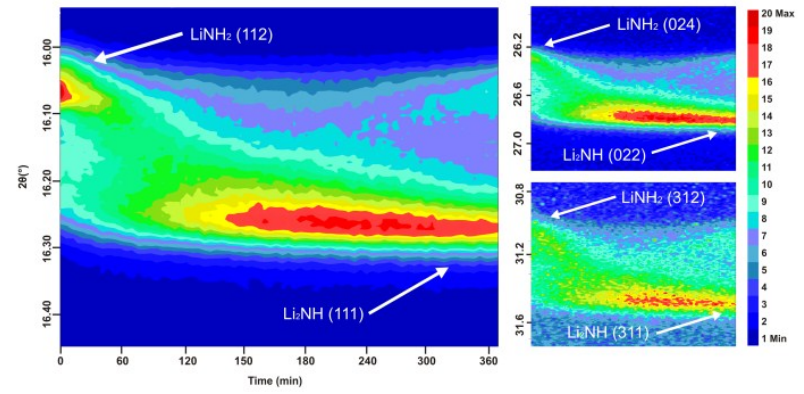

transformation via a continuum of intermediate intensity. Relevant Bragg reflections for $\mathrm{LiNH}_{2}$ and $\mathrm{Li}_{2} \mathrm{NH}$ are indicated on each panel. The colour

5 bar to the right indicates the relative intensity of the diffraction data

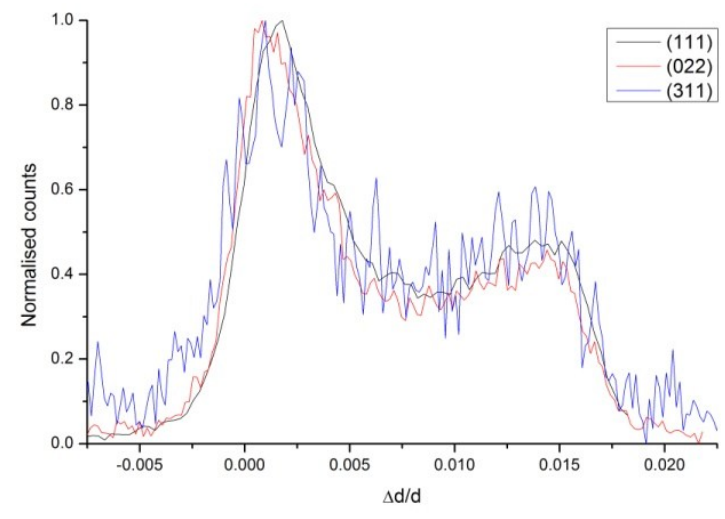

within a panel.

Fig. 5 Strain analysis for three $\mathrm{LiNH}_{2}$ Bragg reflections for the $\mathrm{Li}-\mathrm{N}-\mathrm{H}$ sample obtained at the end of the first dehydrogenation reaction at $290^{\circ} \mathrm{C}$.

Each reflection has had a background subtraction applied before normalisation of the diffraction data for comparison.

which shows a contour plot of four regions of interest in the diffraction data for the first two hydrogenation-dehydrogenation cycles (Processes A-E). Segment (a) shows the (001) reflection of $\alpha-\mathrm{Li}_{3} \mathrm{~N}$, in the angular region $2 \theta=12.16-12.32^{\circ}$. The 15 commercial sample was determined to be free of crystalline impurities, and contains a mixture of $\alpha-$ and $\beta-\mathrm{Li}_{3} \mathrm{~N}$, with the $\beta$ phase converting into the $\alpha$ phase as the sample is heated. ${ }^{28} \alpha$ $\mathrm{Li}_{3} \mathrm{~N}$ is consumed during the hydrogenation according to Equations 1-2, although it can be seen that the phase does not 20 completely disappear until the second hydrogenation.

Segment (b) of Figure 3 shows the region of the diffraction pattern corresponding to the $(002) \mathrm{LiNH}_{2}$ super-lattice reflection, and the $(100) \mathrm{LiNH}_{2}$ reflection $\left(2 \theta=9.10-9.75^{\circ}\right)$. The $(002)$ super-lattice reflection appears as a consequence of the 25 characteristic doubled cubic cell structure of the tetragonal form of $\mathrm{LiNH}_{2}{ }^{29}$. We used this region as the definitive indicator of the presence of tetragonal $\mathrm{LiNH}_{2}$, given that diffraction intensity from some non-stoichiometric Li-N-H phases coincides with the more intense (112), (020) and (024) $\mathrm{LiNH}_{2}$ reflections. As 30 expected, the appearance and disappearance of this reflection correlates well with the hydrogenation and dehydrogenation of the system, respectively. In this segment, we also observe the appearance of a Bragg reflection at a $2 \theta$ value of $9.385^{\circ}$. As the intensity of this reflection follows closely the rise and fall of the
35 (002) reflection, it is assumed that this reflection is the (100) of $\mathrm{LiNH}_{2}$ associated with $\mathrm{LiNH}_{2}$; the $2 \theta$ value is consistent with this assignment. This reflection is not observed for the $I \overline{4}$ structure of $\mathrm{LiNH}_{2}$, leading to the conclusion that the amide is no longer body-centred, and thus we assigned the primitive tetragonal space 40 group $P \overline{4}$ as the appropriate space group for $\mathrm{LiNH}_{2}$ here. For the purposes of our subsequent analysis, we treated $\mathrm{LiNH}_{2}$ as a line phase with $P \overline{4}$ symmetry, and included an anisotropic strain broadening term to account for asymmetry in the peak shape, which may or may not relate to stoichiometry variation.

${ }_{45}$ Segment (c) shows the (002) reflection for lithium hydride (2 $\theta$ $=22.9-23.3^{\circ}$ ), which forms two molar equivalents during the hydrogenation of $\mathrm{Li}_{3} \mathrm{~N}$, with one equivalent consumed and then reformed during the dehydrogenation and hydrogenation of the system between $\mathrm{LiNH}_{2}$ and $\mathrm{Li}_{2} \mathrm{NH}$, respectively. As such, the ${ }_{50} \mathrm{LiH}$ Bragg peak intesntiy is a good indicator of the progression of the reactions in this system.

Segment (d) shows the (112) Bragg peak of $\mathrm{LiNH}_{2}$ and the (111) of $\mathrm{Li}_{2} \mathrm{NH}\left(2 \theta=15.95-16.45^{\circ}\right)$. As the $c$ axis of $\mathrm{LiNH}_{2}$ is approximately double that of $\mathrm{Li}_{2} \mathrm{NH}$ (as an $a \times a \times 2 a$ 55 superstructure), these Miller indices represent analogous planes in each structure. The dominant feature in the data is the transition from the hydrogenated $\mathrm{LiNH}_{2}$ structure to dehydrogenated $\mathrm{Li}_{2} \mathrm{NH}$ through a continuum of intermediate states. The details of this transition will be discussed in greater detail below, but we note ${ }_{60}$ that this observation is clear evidence for the existence of nonstoichiometric phases as proposed by David et al., ${ }^{14}$ and for their intimate involvement in the dehydrogenation mechanism of the Li-N-H system.

High-resolution contour plots for three of these Bragg peak ${ }_{65}$ pairs during the first dehydrogenation reaction (220-660 minutes in Figure 3d) are shown in Figure 4, indicating that the same complex development of the lineshape is observed for all Bragg peak reflections. A more rigorous assessment of this is provided in Figure 5, which depicts a strain analysis for these regions: a 70 plot of the normalised peak intensity in terms of the change in $d$ spacing $(\Delta d)$ across the breadth of the peak divided by the $d$ value for the relevant $\mathrm{LiNH}_{2}$ peak. Figure 4 suggests that the continuum of intermediate states is isotropic in the $\mathrm{Li}-\mathrm{N}-\mathrm{H}$ structure, and therefore is not the result of an alternate microstructural effect 75 such as strain broadening.

Closer examination of the contour plots shown in Figure 4 shows complex stoichiometry variations that are attributable to lithium-ion mobility. Our discussion of these variations divides the non-stoichiometric continuum into three distinct groups: 80 stoichiometry values close to that of $\mathrm{LiNH}_{2} \quad\left(\mathrm{Li}_{1.1} \mathrm{NH}_{1.9}\right.$, $\left.\mathrm{Li}_{1.2} \mathrm{NH}_{1.8}, \mathrm{Li}_{1.3} \mathrm{NH}_{1.7}\right)$ are termed lithium-poor phases, those close to $\mathrm{Li}_{2} \mathrm{NH}\left(\mathrm{Li}_{1.8} \mathrm{NH}_{1.2}, \mathrm{Li}_{1.9} \mathrm{NH}_{1.1}, \mathrm{Li}_{2} \mathrm{NH}\right)$ are termed lithium-rich phases, and the remaining stoichiometry values $\left(\mathrm{Li}_{1.4} \mathrm{NH}_{1.6}\right.$, $\left.\mathrm{Li}_{1.5} \mathrm{NH}_{1.5}, \mathrm{Li}_{1.6} \mathrm{NH}_{1.4}, \mathrm{Li}_{1.7} \mathrm{NH}_{1.3}\right)$ are termed intermediate phases.

85 From 260 minutes (Figure 4), the diffraction signal intensity diverges away from the phases with stoichiometry close to $\mathrm{Li}_{1.5} \mathrm{NH}_{1.5}$, separating into the lithium-poor and lithium-rich end members. This effect can be seen clearly in Figure 6, where the evolution of the molar fraction of each of the refined non90 stoichiometric phases during the dehydrogenation is shown. The lithium-poor phases are seen to increase in magnitude during the latter stages of the reaction at the expense of the intermediate 


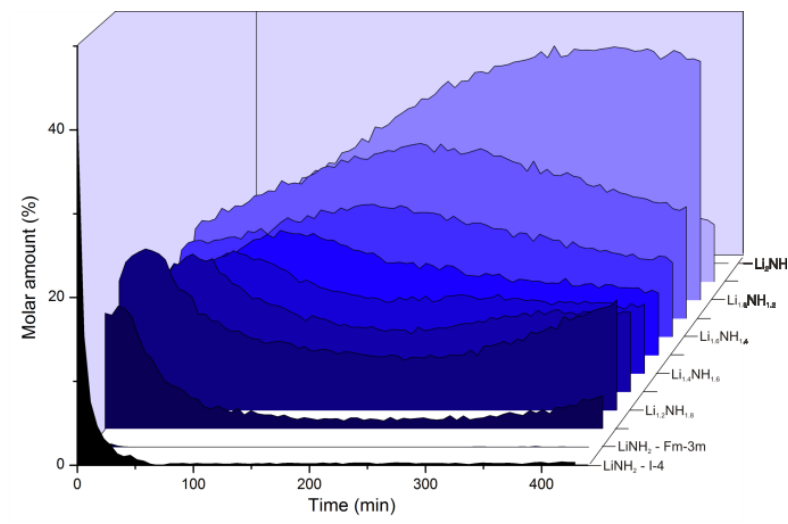

Fig. 6 Stacked plots of the relative molar amounts of each of the refined phases in the $\mathrm{LiNH}_{2}-\mathrm{Li}_{2} \mathrm{NH}$ continuum for the duration of the first dehydrogenation cycle at $290^{\circ} \mathrm{C}$.

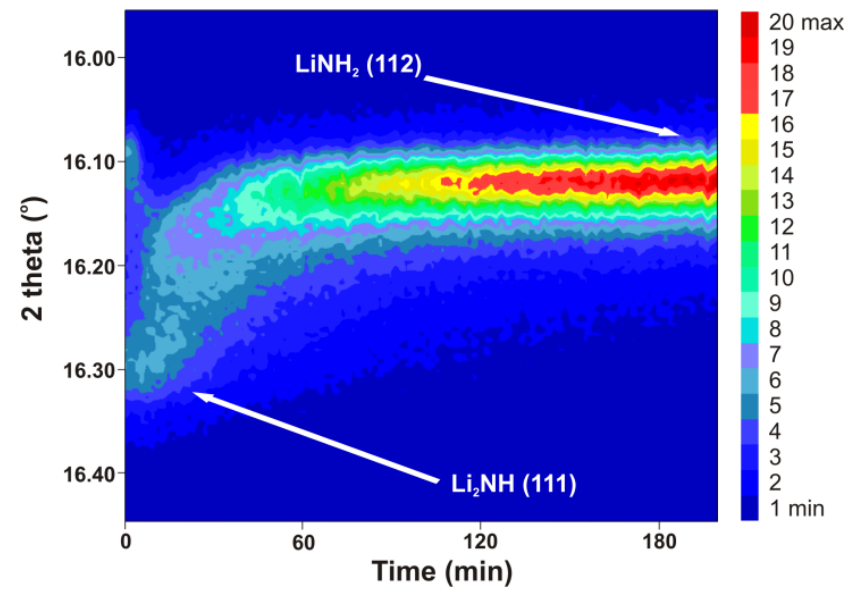

Fig. 7 Contour plot of a section of synchrotron X-ray diffraction data for the hydrogenation of $\mathrm{LiNH}_{2}$ under 0.5 bar of $\mathrm{H}_{2}$ gas at $230^{\circ} \mathrm{C}$, showing the transformation via a continuum of intermediate intensity. Relevant Bragg reflections are indicated. The colour bar to the right indicates the relative diffraction intensity.

10 stoichiometries. The lithium-rich components increase for the duration of the reaction.

The depletion of these intermediate components to produce lithium-rich phases is the normal progression of the reaction from $\mathrm{LiNH}_{2}$ to $\mathrm{Li}_{2} \mathrm{NH}$. However, the simultaneous formation of 15 lithium-poor phases requires further explanation. The reactions outlined in Equations 5-11 do show that $\mathrm{LiNH}_{2}$ is reformed during the dehydrogenation process (Equation 8). However, we expected that this process results in the formation of stoichiometric $\mathrm{LiNH}_{2}$, which is then rapidly consumed to form

20 intermediate range stoichiometry species. Thus it would not be expected to be a mechanism for a net increase in lithium-poor phases.

Moreover, the increase in lithium-poor phases described above occurs at a plateau in the intensity of the $\mathrm{LiH}$ peaks (Figure 3 ), 25 indicating that dehydrogenation reaction is at equilibrium while this process occurs. Taken together, these observations indicate that the intermediate stoichiometry values are of lower stability than the lithium-rich and lithium-poor phases with respect to annealing. This effect is reproduced - albeit in a less dramatic 30 form - for each dehydrogenation reaction observed in this experiment. This instability is consistent with the recent first- principles analysis by Zhang et al., ${ }^{30}$ which showed that the proposed $\mathrm{Li}_{1.5} \mathrm{NH}_{1.5}$ structure is unstable at $\mathrm{T}=0 \mathrm{~K}$ with respect to phase separation into $\mathrm{LiNH}_{2}$ and $\mathrm{Li}_{2} \mathrm{NH}$. Considering the 35 topological similarity of $\mathrm{LiNH}_{2}$ and $\mathrm{Li}_{2} \mathrm{NH}$, this phase separation may be considered to be an ordering of the lithium vacancies within the $\mathrm{Li}_{2} \mathrm{NH}$ structure.

We believe that the intermediate stoichiometry phases are disordered relative to $\mathrm{LiNH}_{2}$ and $\mathrm{Li}_{2} \mathrm{NH}$, and therefore the 40 depletion of these phases is unlikely to be an entropic process, but rather enthalpic or kinetic in nature. It therefore is likely that the ionic mobility of the intermediate stoichiometry values is higher than that of $\mathrm{LiNH}_{2}$ and $\mathrm{Li}_{2} \mathrm{NH}$ because of this intrinsic disorder. Hence, it might be expected that the relative amounts of the end 45 members would increase when a range of stoichiometry values are annealed after the completion of dehydrogenation. Clearly, the relative stability of non-stoichiometric Li-N-H phases is a subject worthy of a future detailed investigation.

The exothermic hydrogenation reaction (Equation 2) is more 50 rapid than the dehydrogenation (reverse of Equation 2) at a given temperature, and so precise observation of the non-stoichiometric intermediates required the use of lower temperatures and hydrogen pressures. One such hydrogenation (Process $\mathrm{K}$ ) is shown in Figure 7. Here, the $\mathrm{Li}_{2} \mathrm{NH}$ (111) and $\mathrm{LiNH}_{2}$ (112) 55 reflections are shown for the hydrogenation at $230^{\circ} \mathrm{C}$ under 0.5 bar of hydrogen. As was the case for the dehydrogenation, it can be seen that the full range of non-stoichiometric phases are formed during the reaction.

The refined phases in the hydrogenated state were found to be 60 a mixture of tetragonal $\mathrm{LiNH}_{2}$ together with smaller amounts of lithium-poor non-stoichiometric cubic phases. Clearly, there must be a point where, as the stoichiometry approaches $\mathrm{LiNH}_{2}$, the structure adopts tetragonal symmetry. ${ }^{14,31}$ This transformation is most clearly marked by the appearance of the (002) super-lattice 65 reflection of tetragonal $\mathrm{LiNH}_{2}$. While the lithium-poor nonstoichiometric phases observed here have long-range cubic symmetry (because the characteristic super-lattice reflections for tetragonal $\mathrm{LiNH}_{2}$ are absent) the short-range order of these phases is anticipated to be tetragonal. It is worth noting that, 70 during dehydrogenation, while the overall rate of dehydrogenation was relatively modest, the disappearance of the super-lattice reflection of $\mathrm{LiNH}_{2}$ is very rapid. This observation is consistent with a reaction model whereby a small deviation in stoichiometry causes the long range tetragonal symmetry to 75 collapse, presumably via a twinning mechanism.

There may be a (small) range of stoichiometry values for which the $\mathrm{Li}-\mathrm{N}-\mathrm{H}$ species retain the long-range tetragonal symmetry of the pure amide phase. The appearance of the (100) reflection described earlier could be indicative of a structural 80 variation with a small shift in the average stoichiometry of longrange-tetragonal $\mathrm{LiNH}_{2}$. However, we did not observe any differences in the relative intensity of the (100) reflection compared to other Bragg peaks in the amide phase during reaction, as would be expected for the interconversion of any

85 such species. Thus, we conclude that loss of body-centring indicates a subtle displacement of the lithium and nitrogen positions, although the exact nature of this displacement remains unclear.

In the previous ex situ synchrotron X-ray diffraction study, ${ }^{14}$ 


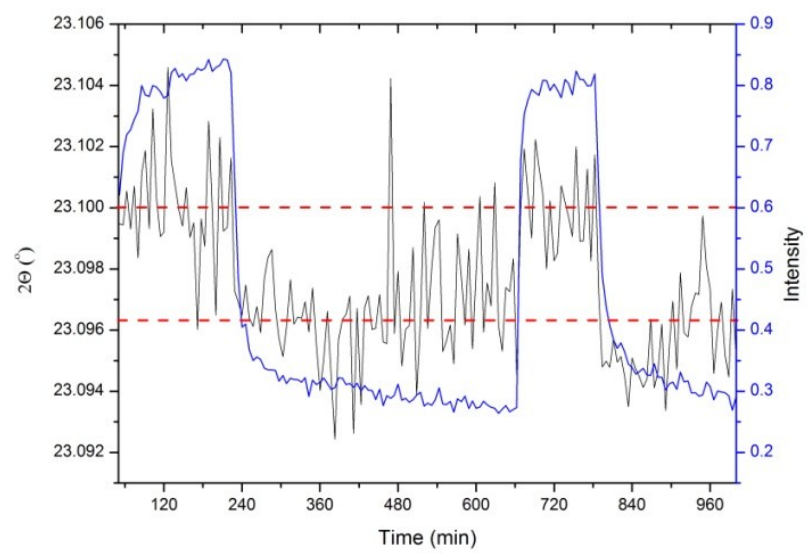

Fig. 8 Peak position and intensity of the (002) reflection of $\mathrm{LiH}$ for the first two hydrogenation-dehydrogenation cycles at $290^{\circ} \mathrm{C}$, obtained from single peak analysis. The average peak positions during hydrogenation and dehydrogenation are shown as dotted lines

5 slightly different lattice constants were observed for lithium hydride in the hydrogenated and dehydrogenated states of the Li$\mathrm{N}-\mathrm{H}$ system. Here, a single peak analysis of the $\mathrm{LiH}(002)$ reflection provides evidence for a change of lattice parameter on hydrogenation, and this is shown in Figure 8. The position and 10 intensity of the peak are shown for the first two hydrogenationdehydrogenation cycles. The average $2 \theta$ position of the peak during hydrogenation is $23.1001(16)^{\circ}$, while the position during dehydrogenation was $23.0963(17)^{\circ}$, with an independent t-test showing the two data sets to be statistically different $(\mathrm{p}<0.01)$.

15 This corresponds to a $0.02 \%$ increase in the lattice constant during dehydrogenation.

Pressure effects alone cannot account for the discrepancy observed in the $\mathrm{LiH}$ lattice parameter on hydrogenation and dehydrogenation, as X-ray diffraction data of $\mathrm{LiH}$ taken under 20 vacuum and 3 bar of hydrogen/helium showed no discernible difference in the peak position (see Supplementary Information). This suggests that there is a significant difference in the defect structure formed during hydrogenation and dehydrogenation. If we consider the role of $\mathrm{LiH}$ in the dehydrogenation reaction, 25 according to Equations 5-8, we understand the formation of hydrogen in the Li-N-H system to result from the action of interstitial hydrogen $\left(\mathrm{H}^{+}\right)$formed in $\mathrm{LiNH}_{2}$ and mobilised in the structure as transitory $\mathrm{NH}_{3}$ units: one of these units may combine with $\mathrm{LiH}$ according to Equation 8, producing $\mathrm{H}_{2}$ and $\mathrm{LiNH}_{2}$.

30 Recent theoretical studies have shown that $\mathrm{LiH}$ is capable of producing interstitial $\mathrm{H}^{-}$ion as part of a Frenkel defect in order to facilitate this reaction. ${ }^{18}$ Thus, the reaction of $\mathrm{LiH}$ with $\mathrm{NH}_{3}$ involves the removal of $\mathrm{H}^{-}$to form $\mathrm{H}_{2}$, and the subsequent reaction of a lithium ion with the $\mathrm{NH}_{2}{ }^{-}$unit to reform $\mathrm{LiNH}_{2}$. The 35 net reaction is therefore the removal of $\mathrm{Li}^{+} / \mathrm{H}^{-}$pairs from the $\mathrm{LiH}$ phase.

We propose that that the increase in the lattice parameter in $\mathrm{LiH}$ during dehydrogenation arises as a result of the formation and removal of these ion pair defects as outlined above. The 40 formation and migration of such defects are known to cause volume expansion in alkali metal halides. ${ }^{32}$ Recently, Symeonides $^{33}$ calculated that the formation of Schottky pairs in $\mathrm{LiH}$ is accompanied by an increase in cell volume as the lattice rearranges around the defect site. We are able to observe this 45 microstructural effect due to the presence of an excess equivalent

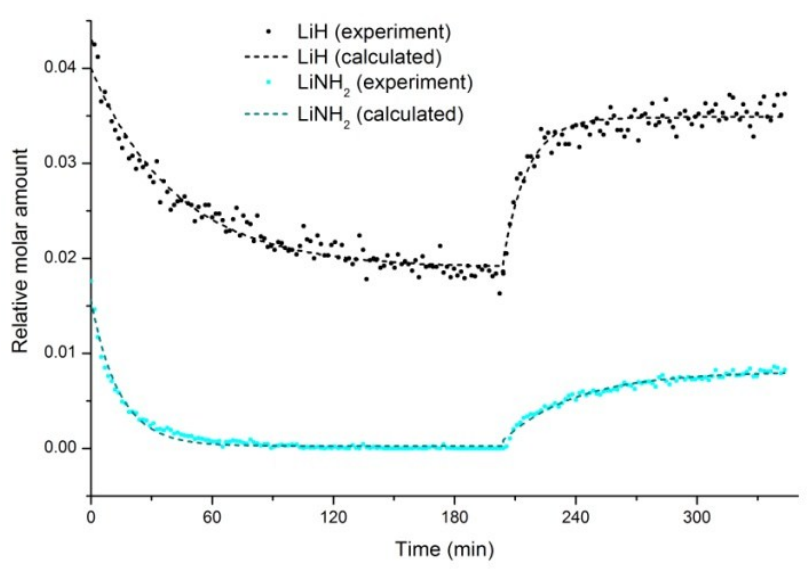

Fig. 9 An example of the kinetic fits of obtained for the dehydrogenation and hydrogenation of the $\mathrm{Li}-\mathrm{N}-\mathrm{H}$ sample at $230^{\circ} \mathrm{C}$. The dots and dashed line represent the experimental and calculated molar amount of each phase, respectively, with black as lithium hydride, and blue as lithium 50 amide.

of lithium hydride from the hydrogenation of $\mathrm{Li}_{3} \mathrm{~N}$. In the isolated $\mathrm{LiNH}_{2} / \mathrm{Li}_{2} \mathrm{NH}$ system, all of the lithium hydride is consumed during dehydrogenation. During hydrogenation, the formation of lithium hydride does not involve the migration of defect species ${ }_{55}$ to the surface, and so the formation of Schottky defects is not expected. Thus, the average cell volume of $\mathrm{LiH}$ is lower during hydrogenation.

One advantage of an in situ X-ray diffraction study is the ability to extract kinetic information from the data. While the data 60 are not of sufficiently high resolution to allow a more detailed analysis of the kinetics through the application of stretched exponentials or other solid state models, ${ }^{34}$ simple exponential models may be fitted to molar amounts extracted from the Rietveld analysis of these data (see Supplementary Information).

${ }_{65}$ An example of the fits obtained for one hydrogen storage and release cycle (Processes $\mathrm{H}-\mathrm{I}$ ) is shown in Figure 9, and the rate constants for $\mathrm{LiH}$ and $\mathrm{LiNH}_{2}$ extracted for all of the reactions are shown in Table 2. These values are formation rate constants during hydrogenation, and consumption rate constants during 70 dehydrogenation.

These rate constants show a significant decrease in the reaction rate with decreasing temperature, as expected. Although only three temperatures were used, the data follow Arrhenius type behaviour $\left(\mathrm{R}^{2}>0.90\right.$ for modelling $\mathrm{LiH}$ and $\mathrm{LiNH}_{2}$ Bragg peak 75 intensity on hydrogenation and dehydrogenation). The rates extracted from the $\mathrm{LiH}$ intensity are equivalent to the overall rate of reaction, and thus the activation energy extracted from the $\mathrm{LiH}$ Arrhenius plot indicated the activation energy of the process. The activation energy extracted is $38(8) \mathrm{kJmol}^{-1}$ for hydrogenation, 80 and $70(15) \mathrm{kJmol}^{-1}$ for dehydrogenation. This implies an enthalpy change for the reaction of $32(17) \mathrm{kJmol}^{-1}$, compared with the expected value of $45 \mathrm{kJmol}^{-1}$ from literature values ${ }^{35}$, and approximately $50-70 \mathrm{kJmol}^{-1}$ from various experimental and theoretical studies. ${ }^{36,9,37}$ The large errors on these values indicate 85 that the approximation to a simple exponential kinetic model is only suitable for a very general description of the kinetics of the system. The activation energy for $\mathrm{LiNH}_{2}$ formation during hydrogenation was found to be $32(10) \mathrm{kJmol}^{-1}$, and $42(9) \mathrm{kJmol}^{-1}$ for consumption during dehydrogenation. 
Table 2 Rate constants from exponential fits to the $\mathrm{LiH}$ and $\mathrm{LiNH}_{2}$ amount for each of the reaction processes in this experiment. Errors in the extracted rate constant are given in brackets.

\begin{tabular}{|c|c|c|c|}
\hline Process & $\begin{array}{l}\text { Starting material, } \\
\text { Reaction conditions }\end{array}$ & $\begin{array}{l}\mathrm{k}(\mathrm{LiH}) \\
\left(\mathrm{min}^{-1}\right)\end{array}$ & $\begin{array}{c}\mathrm{k}\left(\mathrm{LiNH}_{2}\right) \\
\left(\mathrm{min}^{-1}\right)\end{array}$ \\
\hline \multicolumn{4}{|c|}{ Hydrogenation Reactions } \\
\hline A & $\mathrm{Li}_{3} \mathrm{~N}, 290^{\circ} \mathrm{C}, 3$ bar & $0.0651(43)$ & $0.0435(33)$ \\
\hline $\mathrm{C}$ & $\mathrm{Li}_{2} \mathrm{NH}, 290^{\circ} \mathrm{C}, 3$ bar & $0.221(12)$ & $0.0667(46)$ \\
\hline $\mathrm{E}$ & $\mathrm{Li}_{2} \mathrm{NH}, 263^{\circ} \mathrm{C}, 3$ bar & $0.1255(52)$ & $0.061(22)$ \\
\hline G & $\mathrm{Li}_{2} \mathrm{NH}, 235^{\circ} \mathrm{C}, 3$ bar & $0.0822(74)$ & $0.0273(15)$ \\
\hline I & $\mathrm{Li}_{2} \mathrm{NH}, 235^{\circ} \mathrm{C}, 1$ bar & $0.105(14)$ & $0.0419(21)$ \\
\hline $\mathrm{K}$ & $\mathrm{Li}_{2} \mathrm{NH}, 235^{\circ} \mathrm{C}, 0.5 \mathrm{bar}$ & $0.0354(26)$ & $0.0050(8)$ \\
\hline \multicolumn{4}{|c|}{ Dehydrogenation Reactions } \\
\hline B & $\mathrm{LiNH}_{2}, 290^{\circ} \mathrm{C}$ & $-0.0731(44)$ & $-0.1143(31)$ \\
\hline $\mathrm{D}$ & $\mathrm{LiNH}_{2}, 290^{\circ} \mathrm{C}$ & $-0.0632(50)$ & $-0.1199(42)$ \\
\hline $\mathrm{F}$ & $\mathrm{LiNH}_{2}, 263^{\circ} \mathrm{C}$ & $-0.0237(11)$ & $-0.0711(20)$ \\
\hline $\mathrm{H}$ & $\mathrm{LiNH}_{2}, 235^{\circ} \mathrm{C}$ & $-0.022(41)$ & $-0.0519(25)$ \\
\hline $\mathrm{J}$ & $\mathrm{LiNH}_{2}, 235^{\circ} \mathrm{C}$ & $-0.0054(4)$ & $-0.031(10)$ \\
\hline
\end{tabular}

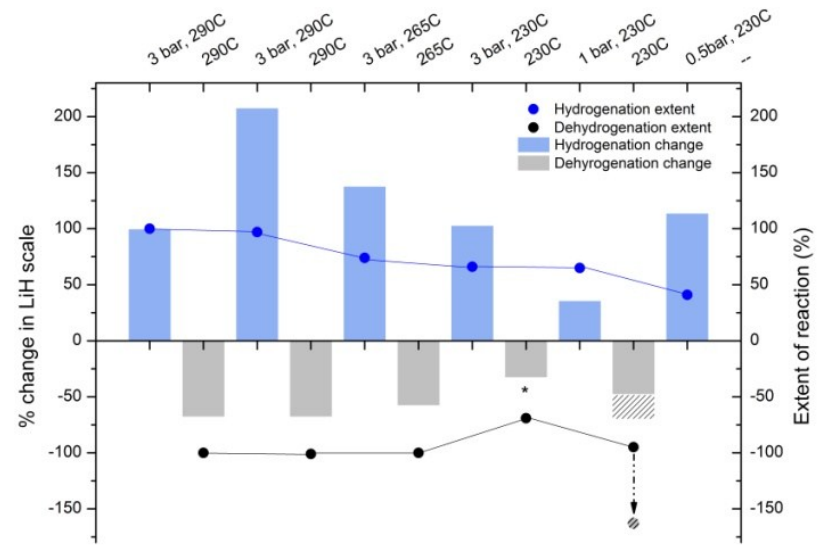

5 Fig. 10 Variation in the magnitude of the $\mathrm{LiH}(002)$ peak during each reaction, shown as a column graph, and the extent of reaction relative to the first hydrogenation-dehydrogenation cycle shown as points. The shaded column and point represent the change in $\mathrm{LiH}$ scale and extent of reaction upon heating the $235^{\circ} \mathrm{C}$ sample to $290^{\circ} \mathrm{C}$. The starred column indicates a partial reaction.

Unlike temperature, the effect of the pressure of hydrogen on the hydrogenation rate is less clear - no simple trend is seen. At a hydrogenation temperature of $235^{\circ} \mathrm{C}$, the rate constant increases from $0.0822(74) \mathrm{min}^{-1}$ with 3 bar $\mathrm{H}_{2}$ to $0.105(14) \mathrm{min}^{-1}$ with 1 15 bar $\mathrm{H}_{2}$, before decreasing to $0.0354(26) \mathrm{min}^{-1}$ with 0.5 bar $\mathrm{H}_{2}$. For the fastest hydrogenation reaction, at $290^{\circ} \mathrm{C}$ with 3 bar $\mathrm{H}_{2}$, the rate constant of $0.221(12) \mathrm{min}^{-1}$ ( $\mathrm{LiH}$ Bragg peaks) translates to a half life for the reaction of 3.14 minutes. Using this result, we would expect the reaction to be $95 \%$ complete in approximately 2012.5 minutes. While vastly superior to the recharge times of current electric vehicles, ${ }^{38}$ this value is significantly in excess of the 2.5 minute target value for vehicular applications, ${ }^{10}$ especially given the high temperature used to achieve that hydrogenation rate in this experiment. The rate could be increased by the use of 25 moderately higher hydrogen pressure, however a trade-off emerges between the speed and practicality of refuelling, principally in terms of heat management during the exothermic refuelling process. For a 12.5 minute refuel of $5 \mathrm{~kg}$ of hydrogen ( $\sim 500 \mathrm{~km}$ range), with an assumed reaction enthalpy of -45 $30 \mathrm{kJmolH}_{2}^{-1}$, the average heat energy generated would be $150 \mathrm{~kW}$. This would require significant heat management.

In addition to the kinetics of the reaction under the various experimental conditions, the relative extent of reaction is of interest, giving insight into the accessible proportion of the stored 35 hydrogen, and the diminution of capacity upon cycling or changes in reaction condition. Given the complexity associated with modelling the Li-N-H region for Rietveld refinement, the $\mathrm{LiH}$ signal is a convenient initial measure of this parameter. Further results from the single peak analysis of the intensity of 40 the (002) reflection of $\mathrm{LiH}$ described earlier are shown in Figure 10 . Here, the average percentage change in the peak during each hydrogenation and dehydrogenation process and an indication of the extent of reaction are shown, taking the first hydrogenation and dehydrogenation endpoints as $100 \%$. It can be seen that the 45 variation in the magnitude of the $\mathrm{LiH}$ peak is significantly greater than the maximum change expected from stoichiometry according to equations $1-2$ ( $-50 \%$ for dehydrogenation and $+100 \%$ for hydrogenation). As such, this analysis is not sufficiently reliable to produce a direct correlation to the $\mathrm{LiNH}_{2}$ ${ }_{50} \mathrm{Li}_{2} \mathrm{NH}$ concentrations. However, the scale of the $\mathrm{LiH}$ peaks can be used as a guide to the relative extent of hydrogenation/dehydrogenation in the system under different reaction conditions.

By this measure, it can be seen that the most significant 55 parameter affecting the hydrogen storage and release capacity of the $\mathrm{Li}-\mathrm{N}-\mathrm{H}$ system is the temperature of the reaction, with the relative extent of hydrogenation from $\mathrm{Li}_{2} \mathrm{NH}$ to $\mathrm{LiNH}_{2}$ dropping from $100 \%$ at $290^{\circ} \mathrm{C}$ to $74 \%$ at $263^{\circ} \mathrm{C}$ and $66 \%$ at $235^{\circ} \mathrm{C}$, and the relative dehydrogenation extent from $\mathrm{LiNH}_{2}$ to $\mathrm{Li}_{2} \mathrm{NH}$ decreasing 60 from $100 \%$ at $290-263^{\circ} \mathrm{C}$ to $95 \%$ at $235^{\circ} \mathrm{C}$. These results suggest that the hydrogenation reaction is more sensitive to changes in temperature at this level than the dehydrogenation reaction, although these observations do not take into consideration any oxidation of the sample by reaction with the capillary, which 65 occurred primarily during. Oxidation, to form lithium oxide $\left(\mathrm{Li}_{2} \mathrm{O}\right)$ will add to the extent of reaction during dehydrogenation measured in this way, as $\mathrm{LiH}$ is likely to be consumed by oxidation. However, it will diminish the extent of reaction of the subsequent hydrogenation, as the lithium from oxidised $\mathrm{LiH}$ is 70 sequestered as lithium oxide. The amount of oxide in the sample from Rietveld refinement of the diffraction data is given in the Supplementary Information. The level increases slowly over the course of the cycling, reaching $16 \mathrm{~mol} \%$ after process I. Very little diminution of capacity was observed for multiple cycles at 75 the same temperature in this experiment.

Hydrogen pressure did not appear to have a significant effect on the extent of hydrogenation over the range of pressures studied at these temperatures, with no significant difference in hydrogenation extent observed for hydrogenations performed at 803.0 bar and 1.0 bar (Processes G and I). The lowest extent of hydrogenation was observed with 0.5 bar $\mathrm{H}_{2}$ (Process K). Examination of the increase in the lithium oxide peak during the previous dehydrogenation (Process J, where an elevated temperature was utilised in an attempt to drive the reaction to 

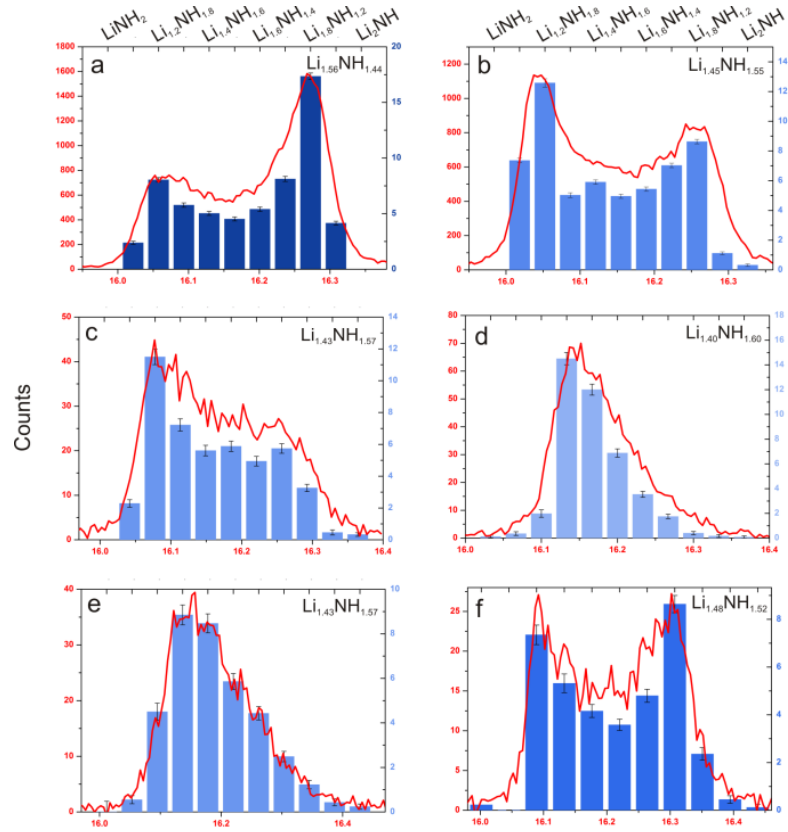

$2 \theta\left({ }^{\circ}\right)$

Fig. 11 Diffraction peak profiles for the Li-N-H region (111) reflection (red) and histograms of refined amounts of $\mathrm{Li}-\mathrm{N}-\mathrm{H}$ phases (blue bars) at the end of dehydrogenation reactions at (a) $290^{\circ} \mathrm{C}$, 1 st cycle (Process B), (b) $290^{\circ} \mathrm{C}, 2$ nd cycle (Process D), (c) $263^{\circ} \mathrm{C}$ (Process F), (d) incomplete 5 reaction at $235^{\circ} \mathrm{C}, 1$ st cycle (Process $\mathrm{H}$ ), (e) $235^{\circ} \mathrm{C}, 2$ nd cycle (Process J), (f) $290^{\circ} \mathrm{C}$, heated from (e). Lighter blue reflects an average stoichiometry values closer to $\mathrm{LiNH}_{2}$, with darker blue closer to $\mathrm{Li}_{2} \mathrm{NH}$. The average stoichiometry of the sample at the end of each dehydrogenation is indicated in the relevant panel.

10 completion), from $16 \mathrm{~mol} \%$ to $38 \mathrm{~mol} \%$ indicates that oxidation of the sample is the most likely explanation for this drop in capacity.

The extent of reaction was also examined by studying the diffraction information for the $\mathrm{LiNH}_{2}-\mathrm{Li}_{2} \mathrm{NH}$ continuum. Figure 1511 shows plots of the diffraction intensity for the Li-N-H region at the end of each dehydrogenation cycle, and a histogram of the refined molar percentage of each non-stoichiometric phase at that point, encompassing the range of reaction temperatures used in the experiment. The average stoichiometry of the sample is 20 indicated in each panel.

A significant difference in behaviour may also be observed between high- and low-temperature dehydrogenation. After hightemperature desorption, a bimodal distribution of the $\mathrm{Li}_{1+x} \mathrm{NH}_{2-x}$ with a slight excess of lithium-rich phases $(x \geq 0.8)$ for cycle 1 25 (11a) and lithium-poor phases $(x \leq 0.2)$ for cycle $2(11 b)$. In figure $11(\mathrm{c})$ and (d), showing the data for dehydrogenation at $263^{\circ} \mathrm{C}$ and $235^{\circ} \mathrm{C}$, respectively, we observe considerably less complete reaction with respect to (a) and (b).

After these low-temperature dehydrogenation reactions, the 30 majority of the phases are in the intermediate $0.3 \leq \mathrm{x} \leq 0.7$ range, with concomitant decreases in the average stoichiometry values relative to the high temperature experiments. A second cycle at $230^{\circ} \mathrm{C}(10 \mathrm{e})$ is visibly similar to the first cycle at $230^{\circ} \mathrm{C}(10 \mathrm{~d})$, although with a slightly increased component of lithium-rich 35 phases.

The high-temperature phase composition profiles shown in Figure 11 indicate a system where ionic mobility is the limiting factor, with a roughly even distribution of lithium-rich and -poor phases. The excess of lithium rich phases in Figure 11(a) may be 40 attributed to this material approaching complete dehydrogenation and the more even profile of phases in the second cycle at $290^{\circ} \mathrm{C}$ (Figure 11b) resulting from incomplete dehydrogenation. With low-temperature dehydrogenation, the phase composition profiles of Figure 11(c)-(e) suggests a system where the process of the 45 reaction is limited by temperature, (i.e.) there is insufficient thermal energy to form the most lithium-rich compositions. This, in turn, suggests the presence of a different activation barrier for lithium/proton migration in lithium-poor materials compared to lithium-rich materials. The structural similarity of the amide and ${ }_{50}$ imide phases notwithstanding, this is to be expected as lithium amide has many more vacant potential hopping sites for lithium cations and protons than the imide. Furthermore, the driving potential for lithium motion - the negative charge of the $\mathrm{NH}^{2-}$ unit - is more shielded in lithium rich compounds, and the 55 potential for $\mathrm{Li}^{+}-\mathrm{Li}^{+}$repulsion (ionic conductivity scattering events) is greater where there is a greater concentration of lithium cations. The variation in activation barrier has also been reported to arise from a difference in high temperature behaviour of $\mathrm{NH}_{2}^{-}$ and $\mathrm{NH}^{2-} \cdot{ }^{39}$ For the sample with an initial dehydrogenation ${ }_{60}$ temperature of $235^{\circ} \mathrm{C}$, followed by an increase in temperature to $290^{\circ} \mathrm{C}$, we see a greater concentration of lithium-rich phases, but also a relatively high concentration of lithium-poor phases. The bimodal distribution seen with increased temperature indicates enhanced stability for the end members of $\mathrm{Li}_{1+x} \mathrm{NH}_{2-x}$ compared 65 with the intermediate compositions, as described earlier.

In this investigation, we have observed the dual effects of kinetic and thermodynamic stability on the Li-N-H system. The facile reversibility of the hydrogen storage reactions in this system is facilitated by the formation of non-stoichiometric 70 phases $\left(\mathrm{Li}_{1+\mathrm{x}} \mathrm{NH}_{2-\mathrm{x}}\right)$, which appear to be stabilised because of their disordered nature (and thus, high ionic conductivity). However, the relative thermodynamic stability of these phases is low compared with the end members, $\mathrm{LiNH}_{2}$ and $\mathrm{Li}_{2} \mathrm{NH}$, and so with annealing, and increased temperature, phase separation into 75 these species is observed. These dual effects are illustrated by the comparison of Figure 11 (e) and (f), where the heating of the sample from $235^{\circ} \mathrm{C}$ to $290^{\circ} \mathrm{C}$ under vacuum facilitates the transformation from the kinetic distribution of phases seen in the low temperature reaction (e) to the bimodal thermodynamic 80 distribution seen at high temperatures (f). We believe the close interplay of these effects is central to the reversibility of the Li-NH system.

In addition to the possibility of differential stability and ionicmobility barriers, particle-size equilibration may play an 85 important role in the dehydrogenation kinetics and extent of reaction. Particle size has been suggested to influence the balance between bulk/surface mechanisms in the Li-N-H system. ${ }^{17,18}$ Given the doubling of lithium density during dehydrogenation, it is not unreasonable to assume that the $\mathrm{LiNH}_{2} / \mathrm{Li}_{2} \mathrm{NH}$ particles 90 decrepitate during this process. However, the initial particle sizes of the $\mathrm{LiNH}_{2}$ and $\mathrm{LiH}$ may play a significant role in the extent of reaction for a given temperature. The samples in this experiment were hand ground, but mechanochemical milling has been shown to reduce the activation energy for the reaction. ${ }^{40,41}$ This may be 95 reflected in the fact that, even at the highest temperatures used in this experiment, the extent of reaction as determined from the 
average stoichiometry of the Li-N-H phases was $56 \%$.

The results of this study make the clear point that improving ionic conductivity and maintaining that mobility with cycling are key goals in the commercial development of the Li-N-H 5 hydrogen store. Optimisation of this characteristic feature is the most promising route to a lowering of the practical operating temperature of the system. Indeed, studies on the insertion of halide anions into the lithium amide structure have delivered lower desorption temperatures. ${ }^{42}$ Further work of this type is 10 needed, ideally without the hydrogen storage capacity diminishment which naturally accompanies halide substitution.

\section{Conclusion}

Through in situ synchrotron powder X-ray diffraction, nonstoichiometric intermediates of the form $\mathrm{Li}_{1+\mathrm{x}} \mathrm{NH}_{2-\mathrm{x}}$ are shown to 15 be integral to the mechanism of both hydrogenation and dehydrogenation of the Li-N-H system. These observations are consistent with a proposed Frenkel defect model ${ }^{14}$ for these reactions, underlining the importance of ionic mobility for the facile reversibility of the system.

20 Examination of the rates and endpoints of reaction under different conditions emphasises the crucial role of ionic mobility in determining the practical use of this material, with limited formation of lithium-phases as the temperature is lowered. While showing that non-stoichiometric phases of the form $\mathrm{Li}_{1+x} \mathrm{NH}_{2-x}$ 25 are integral to the reaction mechanism of the Li-N-H system, we also observed the thermodynamic instability of intermediate stoichiometry components $\left(\sim \mathrm{Li}_{1.5} \mathrm{NH}_{1.5}\right)$ towards ordering/phase separation into $\mathrm{LiNH}_{2}$ and $\mathrm{Li}_{2} \mathrm{NH}$. This effect may be explained by the different barriers to diffusion in the end member phases 30 relative to the intermediate species.

These results highlight potential avenues for reducing capacity loss in the system, as well as exploring the nature of the temperature limitation on reversible hydrogen capacity. The research challenges which must be addressed if the Li-N-H 35 system and derivatives thereof are to be commercially viable in the transportation sector are clear. Increased efforts to understand the energy barriers to the further dehydrogenation of nonstoichiometric phases, as well as the ionic mobility and local structures of these phases, may provide avenues towards lowering 40 the functional temperature of the system.

It is clear that, in the most promising complex hydride hydrogen stores (Li-N-H, Li-Mg-N-H and sodium alanate), the mobility of ionic defects is the key to reversibility. With regard to the development of derivatives of these systems, and of new

45 complex hydride hydrogen stores, it is evident that this intrinsic characteristic should be used as a screening tool in the search for promising solid state hydrogen storage materials. This route offers the best potential for feasible hydrogen-powered transportation based on complex hydride materials.

\section{${ }_{50}$ Acknowledgements}

The authors would like to acknowledge Diamond Light Source (UK) for the provision of experimental time, and the Research Complex at Harwell for the use of laboratory space and equipment. Dr Chiu Tang and Dr Julia Parker are thanked 55 gratefully for their assistance with the collection of the diffraction data. PPE thanks the EPSRC for their continued support. JWM thanks the Rhodes Trust for funding.

\section{Notes and references}

${ }^{a}$ Inorganic Chemistry Laboratory, University of Oxford, South Parks 60 Road, Oxford, UK, OX1 3QR

${ }^{b}$ ISIS Facility, Rutherford Appleton Laboratory, Chilton, Didcot, UK, OX110QX

"Email: bill.david@stfc.ac.uk

$\dagger$ Electronic Supplementary Information (ESI) available: [Experimental 65 details and temperature calibration. Refinement details, refined data and contour plots of X-ray data for each reaction. Refined phase amounts for each reaction. Refined data plots for lithium hydride under hydrogen and helium pressure, and vacuum. Kinetic analysis details for lithium hydride and lithium amide.]. See DOI: 10.1039/b000000x/

70

1. L. Schlapbach and A. Züttel, Nature, 2001, 414, 353-358.

2. W. Grochala and P. P. Edwards, Chemical reviews, 2004, 104, 1283-316.

3. M. Schwickardi and B. Bogdanovic, Journal of Alloys and 75 Compounds, 1997, 254, 1-9.

4. W. I. F. David, Faraday Discussions, 2011, 151, 399.

5. P. Chen, Z. Xiong, J. Luo, J. Lin, and K. L. Tan, Nature, 2002, 420, 302-4.

6. P. Chen, Z. Xiong, J. Luo, J. Lin, and K. L. Tan, Journal of

80 Physical Chemistry B, 2003, 107, 10967-10970.

7. F. E. Pinkerton, Journal of Alloys and Compounds, 2005, 400, 76-82.

8. W. Osborn, T. Markmaitree, and L. L. Shaw, Nanotechnology, 2009, 20, 204028.

$859 . \quad$ S. Isobe, T. Ichikawa, K. Tokoyoda, N. Hanada, H. Leng, H. Fujii, and Y. Kojima, Thermochimica Acta, 2008, 468, 35-38.

10. US Department of Energy, Targets for Onboard Hydrogen Storage Systems for Light-Duty Vehicles, 2009.

11. T. Ichikawa, N. Hanada, S. Isobe, H. Leng, and H. Fujii, 90 Journal of Physical Chemistry B, 2004, 108, 7887-7892.

12. S. Isobe, T. Ichikawa, S. Hino, and H. Fujii, Journal of Physical Chemistry B, 2005, 109, 14855-8.

13. Y. H. Hu and E. Ruckenstein, Journal of Physical Chemistry A, 2003, 107, 2-4.

$9514 . \quad$ W. I. F. David, M. O. Jones, D. H. Gregory, C. M. Jewell, S. R. Johnson, A. Walton, and P. P. Edwards, Journal of the American Chemical Society, 2007, 129, 1594-601.

15. T. W. D. Farley, W. Hayes, S. Hull, M. T. Hutchings, and M. Vrtis, Journal of Phyisics: Condensed Matter, 1991, 3, 4761$100 \quad 4781$

16. M. Hayoun, M. Meyer, and A. Denieport, Acta Materialia, 2005, 53, 2867-2874.

17. G. Miceli, C. S. Cucinotta, M. Bernasconi, and M. Parrinello, Journal of Physical Chemistry C, 2010, 114, 15174-15183.

10518 K. Hoang, A. Janotti, and C. G. Van de Walle, Physical Review $B, 2012, \mathbf{8 5}, 064115$.

19. E. Hazrati, G. Brocks, B. Buurman, R. A. De Groot, and G. A. De Wijs, Physical Chemistry Chemical Physics, 2011, 13, 6043-6052.

$11020 . \quad$ W. Li, G. Wu, Z. Xiong, Y. P. Feng, and P. Chen, Physical chemistry chemical physics : PCCP, 2012, 14, 1596-606.

21. B. A. Van Hassel, J. M. Pasini, R. C. Mcgee, J. R. Karra, A. M. Limarga, J. Holowczak, I. Fedchenia, J. Khalil, J. C. Rampone, and R. Brown, Advancement of Systems Designs and Key

115 Engineering Technologies for Materials Based Hydrogen Storage, 2012.

22. T. Ichikawa, N. Hanada, S. Isobe, H. Y. Leng, and H. Fujii, Journal of Alloys and Compounds, 2005, 404-406, 435-438.

23. S. Isobe, T. Ichikawa, N. Hanada, H. Y. Leng, M. Fichtner, O.

120 Fuhr, and H. Fujii, Journal of Alloys and Compounds, 2005, 404-406, 439-442.

24. T. Ichikawa, S. Isobe, N. Hanada, and H. Fujii, Journal of Alloys and Compounds, 2004, 365, 271-276. 
25. J. Lamb, D. Chandra, W.-M. Chien, D. Phanon, N. Penin, R. Černý, and K. Yvon, The Journal of Physical Chemistry C, 2011, 115, 14386-14391.

$26 . \quad$ J. E. Parker, J. Potter, S. P. Thompson, A. R. Lennie, and C. C.

5 Tang, Materials Science Forum, 2012, 706-709, 1707-1712.

27. A. Coelho,

28. O. Palumbo, a Paolone, R. Cantelli, and D. Chandra, International Journal of Hydrogen Energy, 2008, 33, 31073110 .

$1029 . \quad$ S. Isobe, S. Ohnuki, W. I. F. David, M. Gutmann, M. O. Jones, P. P. Edwards, T. Ichikawa, and Y. Kojima, International Journal of Hydrogen Energy, 2011, 36, 7909-7913.

30. F. Zhang, Y. Wang, and M. Chou, Physical Review B, 2010, 82, $1-6$.

15 31. R. Juza, Angewandte Chemie (International ed. in English), 1964, 3, 471-481.

32. D. N. Yoon and D. Lazarus, Physical Review B, 1972, 5, 49354945.

33. C. I. Symeonides, Journal of Alloys and Compounds, 2009,

$20 \quad 478,820-822$.

34. A. Khawam and D. R. Flanagan, Journal of Physical Chemistry $B, 2006,110,17315-17328$.

35. D. R. Lide, Ed., CRC Handbook of Chemistry and Physics, 88th Edition, CRC Press, 2007.

$2536 . \quad$ T. Tsumuraya, T. Shishidou, and T. Oguchi, Journal of Alloys and Compounds, 2007, 446-447, 323-327.

37. S. Hino, N. Ogita, M. Udagawa, T. Ichikawa, and Y. Kojima, Journal of Applied Physics, 2009, 105, 023527.

38. Tesla Motors, .

30 39. A. Blomqvist, C. Moysés Araújo, R. Scheicher, P. Srepusharawoot, W. Li, P. Chen, and R. Ahuja, Physical Review B, 2010, 82, 1-5.

40. R. A. Varin, M. Jang, and M. Polanski, Journal of Alloys and Compounds, 2010, 491, 658-667.

${ }_{35} 41 . \quad$ L. L. Shaw, R. Ren, T. Markmaitree, and W. Osborn, Journal of Alloys and Compounds, 2008, 448, 263-271.

42. P. A. Anderson, P. A. Chater, D. R. Hewett, and P. R. Slater, Faraday Discussions, 2011, 151, 271. 